\title{
La investigación y la literatura especializada en Información y Documentación: una revisión
}

\author{
Dra. Maㅡ Eulalia Fuentes i Pujol \\ Alfons González Quesada \\ Àrea de Documentació \\ Universitat Autònoma de Barcelona
}

\subsection{Resumen}

Revisión de la evolución de la investigación sobre Ciencias de la Documentación en España. Se analizan los agentes institucionales de la investigación - universidades, asociaciones profesionales y empresas-, los principales cauces de publicación — las revistas especializadas - y los foros públicos más importantes — congresos y jornadas-, Seguidamente, se atiende a los productos de la actividad, señaladamente los programas de educación oficiales —en primer, segundo y tercer ciclo- y de formación permanente, la evolución de las publicaciones - revistas, monografías, artículos y tesis-. A través de todos estos indicadores, se documenta el proceso de crecimiento, con un despegue de la investigación durante la década de los noventa, la importancia decisiva en este proceso de la proliferación y consolidación de las unidades docentes por todos el país, y la necesidad de progresar desde una fase de investigación generalista hacia la especialización y la investigación aplicada.

Palabras clave: Información y documentación. Producción científica. Proyectos de investigación. Reuniones científicas. España.

\subsection{Abstract}

The evolution of research on Library and Information Science in Spain is reviewed. The institutional research agents —universities, professional associations and companies-, publishing networks — specialised journals - and main public meetings - congresses and meetings - are analysed. Thereafter, the products of the research activity are considered, mainly official educational programmes - at pregraduate, postgraduate and doctoral levels-and permanent education ones, the evolution of publications - journals, monographies, articles and thesis- . Through all these indicators, a process of growth is documented, with a strong take off in the nineties, due to the proliferation and consolidation of 
new university groups all over the country. A need to progress from a generalist research phase towards a specialised and applied one is defended.

Keywords: Information and documentation. Scientific production. Research projects. Scientific meetings. Spain.

\section{La investigación en Información y Documentación}

Estamos inmersos en una sociedad que necesita gran cantidad de información y la necesita de forma rápida y constante. El ritmo de crecimiento de la información producida por nuestra sociedad es exponencial. La mayoría de las actividades humanas generan y consumen información, y en algunas la información se convierte en una necesidad imperiosa en la investigación, en la industria y en los medios de comunicación. Carecer de la información precisa y adecuada puede acarrear serias consecuencias en todos los ámbitos: el derecho, la química, la medicina, la comunicación, y por supuesto en el de la Documentación. En nuestro campo cada día existen más publicaciones, se realizan más estudios e investigaciones, se ponen en marcha muchos proyectos y aplicaciones. El análisis de toda esta problemática es el objetivo de la ponencia que presentamos. Analizar la investigación actual en el sector de la Información y Documentación, señalar su evolución y hacer una revisión de la literatura especializada, son tres de los puntos clave que permitirán poder ver el estado en el que se halla la producción de información y de la investigación en el ámbito de la Documentación.

Para poder hablar de la investigación en Información y Documentación en España, es necesario hacer un poco de historia de sus orígenes, tendencias, evolución, etc. Los orígenes de la Documentación en España se remontan a la década de los 60, mucho más tarde que en otros países. En términos generales en España se puede hablar de tres grandes tendencias históricas, unidas a las tres grandes disciplinas (Fuentes, 1997, p. 35-36):

- Documentación: En ella se sitúa a J. Lasso de la Vega, que se puede considerar el introductor del concepto de Documentación en España y el primer estudioso del tema. Fue el que escribió el primer Manual de Documentación (1969). Junto con J. Roger Rivière y J. R. Pérez ÁlvarezOssorio pueden situarse dentro de la corriente Documental. Todos ellos hablan de la Documentación como una disciplina más amplia que la Biblioteconomía. Pero, mientras Lasso de la Vega la denomina Documentación, Roger Rivière habla de Documentación Científica y Pérez Álvarez-Ossorio de Información y Documentación Científica.

- Biblioteconomía:La tendencia o corriente biblioteconómica está representada por L. García Ejarque. Para él las profesiones de bibliotecario espe- 
cializado, documentalista y científico de la información eran una sola. Esta tendencia es seguida por la mayoría de bibliotecarios.

- Archivística: Representada por L. Sánchez Belda y C. Pescador del Hoyo, que consideran la Documentación - a la que denominan Documentología o Documentalismo - como una técnica auxiliar de la investigación y una actividad que gira alrededor de los documentos.

- Teledocumentación: El concepto aparece en España en 1973, con la firma del acuerdo del Instituto Nacional de Técnicas Aeroespacial (INTA) y la European Space Research Organisation (ESRO), hoy Agencia Europea del Espacio (ESA), el 21 de mayo de 1973, según el cual daba acceso a la información del Space Documentation Service (SDS) de ESRO. Su consolidación puede situarse a finales de 1979.

La investigación en Información y Documentación, así como también la formación de la disciplina y del concepto se puede enmarcar alrededor de tres grandes núcleos, las asociaciones profesionales, los núcleos docentes y las revistas especializadas, de las que se hablará en el apartado de producción científica.

\subsection{Las asociaciones profesionales}

Aunque los objetivos y las funciones de las asociaciones profesionales se basan fundamentalmente en la defensa de los intereses profesionales, en su representación ante otros órganos nacionales e internacionales y su contribución a la formación continua de sus asociados; también, a través fundamentalmente del establecimiento de grupos de trabajo, suelen intercambiar información, organizar seminarios o conferencias, promover y realizar investigaciones, proyectos, informes, memorias, estudios generales y específicos sobre distintos temas de interés para su colectivo profesional. Además prácticamente todas las asociaciones editan algún tipo de publicación, aunque sólo sea un boletín informativo.

Adelaida Roman (Mayo 1994, p. 17) propuso en 1994 agrupar las actividades de las asociaciones en cuatro categorías, y asignó un peso relativo a cada una de las actividades en el conjunto de las asociaciones. Actualmente dichas categorías y pesos siguen siendo válidos (Figura 1, en la siguiente página).

Con excepción de la Asociación de Archiveros, Bibliotecarios y Arqueólogos (ANABA) creada en 1949, pero cuyo proceso de constitución no cristaliza legalmente hasta 1978, y de la Agrupació d'Antics Alumnes i Ex alumnes de l'Escola de Bibliotecaris de Barcelona (1931), las demás asociaciones no nacen hasta las décadas de los años setenta y ochen ta, sobre todo a partir de la constitución de las autonomías.

Existen unas asociaciones que tienen nivel estatal, en muchos casos con delegaciones en las distintas comunidades autónomas, como, por ejemplo, el

Scire. $7: 2$ (jul.-dic. 2001) 11-38. 
caso de $\mathrm{ANABAD}$, y otras con un ámbito territorial definido, mayoritariamente una comunidad autónoma (Tabla 1).

\section{Los núcleos docentes}

Históricamente se puede hablar de tres núcleos docentes — por orden de importancia Madrid, Barcelona y Valencia- que han desarrollado las teorías biblioteconómica y documental, puesto que hasta la consolidación del Estado de las Autonomías a finales de la década de los 80 no empiezan a surgir nuevos núcleos en Andalucía y País Vasco y, posteriormente, en Aragón, Canarias, Castilla y León, Extremadura, Galicia y Murcia. (Fuentes, 1997, p. 39 ss.)

\subsection{Núcleo docente de Madrid}

En 1900 al desaparecer la Escuela Superior de Diplomática, algunas de las materias impartidas en ella, se incorporaron a la Sección de Historia de la Facultad de Filosofía y Letras de la Universidad de Madrid (más tarde Universidad Complutense de Madrid). Ello supuso la casi práctica desaparición de los estudios de Biblioteconomía, y la formación académica quedó reducida a un temario de oposiciones - puesto que éstas siguieron convocándose- y a un cuerpo de funcionarios. Por lo tanto, el perfil del profesional fue, en esta primera época, el de licenciado en Filosofía y Letras, con una pequeña formación suplementaria, impartida por el Cuerpo de Funcionarios mediante pequeñas academias.

No fue hasta 1956 cuando la Sección de Filosofía Románica de la ya Universidad Complutense de Madrid, introdujo la asignatura Bibliografía Hispánica y Metodología de la Investigación Literaria, consolidada en 1970, cuando se creó esta cátedra, núcleo difusor de las enseñanzas bibliográficas en España.

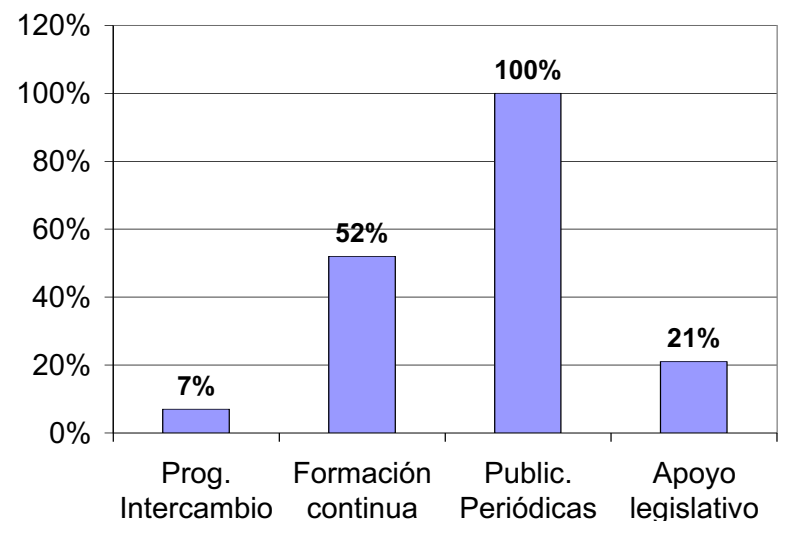

Figura 1. Actividades de las asociaciones profesionales

Scire. $7: 2$ (jul.-dic. 2001) 11-38. 
En 1947 la Dirección General de Archivos y Bibliotecas creó la llamada Escuela de Formación Técnica de Archivos, Bibliotecas y Museos, ofreciendo cursos de formación en Madrid y en Barcelona. Estos cursos se convirtieron en 1964 en la Escuela de Documentalistas (1964-1979), ubicada en el edificio de la Biblioteca Nacional. En 1977 y con la creación del Ministerio de Cultura y la Dirección General del Libro y Bibliotecas y la Subdirección General de Bibliotecas, la Escuela de Documentación pasa a denominarse Escuela de Bibliotecarios, y, finalmente en 1980, Centro de Estudios Bibliográficos y Documentarios (1980-1986).

En 1969 al crearse la Universidad Autónoma de Madrid, se crea también el actual Gabinete de Documentación Científica, adscrito al Departamento de Química. Al principio se preocupó de tareas principalmente biblioteconómicas (servicios de bibliotecas y documentación), y más adelante asumió tareas docentes, organizando diversos cursos e investigaciones. En 1971 se aprueba la inclusión de la asignatura "Información y Documentación Científica" en el primer ciclo de la Facultad de Ciencias de esta universidad.

En la Universidad Complutense de Madrid existen dos facultades distintas que imparten enseñanzas en este ámbito: la Facultad de Filosofía y la de Ciencias de la Información. Durante el curso 1971-72 comienza a impartirse en la Universidad Complutense de Madrid y en la Autónoma de Barcelona los estudios de Ciencias de la Información, que tienen previsto en su plan la realización de la asignatura Documentación en quinto curso de las tres ramas, Periodismo, Publicidad e Imagen. En Barcelona, como se verá más adelante, sólo se impartían las dos primeras.

El Departamento de Documentación de la Facultad de Ciencias de la Información de la Universidad Complutense de Madrid, constituido en 1978, crea la llamada Escuela de Documentación dirigida a postgraduados, que otrogaba el título de Especialista Universitario en Documentación.

Finalmente, se debe hablar también de distintos cursos y seminarios organizados por profesionales y por instituciones y/o empresas públicas y privadas, que han llenado el vacío formativo durante muchos años en este ámbito. Entre ellos pueden citarse, entre otros, los cursos de la Sociedad Española de Documentación e Información ( SEDIC); la Asociación Nacional de Archiveros, Bibliotecarios y Museólogos y Documentalistas (ANABAD); FUINCA; el Instituto de Ciencia y Tecnología (ICYT) y el Instituto de Ciencias Sociales y Humanidades (ISOC), ambos pertenecientes al Consejo Superior de Investigaciones Científicas (CSIC); el Instituto Internacional de Madrid en colaboración con la Universidad de California del Sur (1966-1978). 


\subsection{Núcleo docente de Barcelona}

En Cataluña la situación era un poco distinta a la del resto de España, ya que para la formación de las profesionales se crea en Barcelona la Escola Superior de Bibliotecàries, (1915-1924) que garantiza su formación. En julio de 1925 y coincidiendo con la supresión de la Mancomunitat de Catalunya, l'Escola Superior de Bibliotecàries pasa a depender de la Diputación de Barcelona y se crea la Escuela Superior para la Mujer (1924-1930), donde los estudios de biblioteconomía constituían sólo un apartado, aunque la sección o carrera con más entidad fuese la llamada de Bibliotecarias, Archiveras y Funcionarias.

Después del lapso de la Dictadura de Primo de Rivera y con la supresión de la Escuela Superior para la Mujer y la creación en julio de 1930 de la Escola de Bibliotecàries (1930-1939), se inicia una nueva etapa muy parecida a la primera,

\begin{tabular}{|c|c|}
\hline ASOCIACIONES & NOMBRE Y SIGLAS \\
\hline ESTATALES & $\begin{array}{l}\text { Asociación de Archiveros, Bibliotecarios, Museólogos y Documentalistas (ANABAD) } \\
\text { Sociedad Española de Documentación e Información Científica (SEDIC) } \\
\text { Asociación de titulados universitarios en Documentación y Biblioteconomía (ADAB). } \\
\text { Federación Española de Sociedades de Archivística, Biblioteconomía y Documentación } \\
\text { (FESABID) * }\end{array}$ \\
\hline $\begin{array}{c}\text { ÁMBITO } \\
\text { TERRITORIAL } \\
\text { ESPECIFICO }\end{array}$ & $\begin{array}{c}\text { ANDALUCIA } \\
\text { Asociación Andaluza de Bibliotecarios (AAB) } \\
\text { Asociación Andaluza de Documentalistas (AAD); } \\
\text { ASTURIAS } \\
\text { Asociación Asturiana de Bibliotecarios, Archiveros y Documentalistas y Museólogos } \\
\text { (AABADOM) } \\
\text { BALEARES } \\
\text { Asociació de Bibliotecaris, Arxivers i Documentalistes de les Illes Balears (ADADIB) } \\
\text { CANARIAS } \\
\text { Asociación de Bibliotecarios de las Islas Canarias. } \\
\text { CATALUÑA } \\
\text { Associació d'Arxivers de Catalunya (ACC) } \\
\text { Coordinadora de Documentació Biomèdica } \\
\text { EXTREMADURA } \\
\text { Col.legi Oficial de Bibliotecaris-Documentalistas de Catalunya (COBD) ** } \\
\text { Asociación de Bibliotecarios, Archiveros y Documentalistas y Museólogos de Extremadura } \\
\text { (ABADMEX) } \\
\text { PAIS VASco } \\
\text { Asociación de Bibliotecarios y Documentalistas de Guipúzcoa } \\
\text { Asociación Vasca de Archiveros, Bibliotecarios y Documentalistas (ALDEE } \\
\text { VALENCIA } \\
\text { Associació Valenciana d' Especialistes en Información (AVEI) }\end{array}$ \\
\hline
\end{tabular}

\footnotetext{
*Actualmente aglutina trece asociaciones de distintas zonas geográficas de todo el Estado.

**Tiene su origen en la Agrupació d'Antics Alumnes i Ex alumnes de l'Escola de Bibliotecaris de Barcelona . En 1999 se fusionó con la Societat Catalana de Documentació i Informació SOCADI.
}

Tabla 1. Asociaciones profesionales

Scire. $7: 2$ (jul.-dic. 2001) 11-38. 
pero aún más fructífera, con una gran influencia anglosajona y una gran proyección exterior, bajo la dirección de Jordi Rubió i Balaguer.

Finalizada la Guerra Civil y suprimida la Generalitat de Catalunya, la Escola de Bibliotecàries y la Red de Bibliotecas Populares pasan nuevamente a depender de la Diputación de Barcelona. Pero su inserción dentro del sistema educativo español sigue siendo difícil y no se reconocen los estudios hasta 1978. No es hasta finales del franquismo que se convierte en escuela mixta y cambia de nombre por el de Escola de Bibliologia (1974). Finalmente en 1982 se convierte en escuela universitaria adscribiéndose a la Universidad de Barcelona bajo el nombre Escola Universitària “Jordi Rubió i Balaguer" de Biblioteconomía i Documentació.

Al igual que en la Universidad Complutense de Madrid, durante el curso 1971-72 se empieza a impartir en la Universidad Autónoma de Barcelona la Licenciatura en Ciencias de la Información, que incluía en quinto curso la asignatura de "Documentación", tanto en Periodismo como en Publicidad.

Al igual que había ocurrido en Madrid, surgen cursos y seminarios organizados por la propia profesión, por distintas instituciones públicas y privadas, o por los distintos centros de documentación que van apareciendo, verdaderos pioneros en este campo. Este es el caso - en una primera época- del Centre de Documentació d'Enginyeria (CEDIN) creado el 1973, el Consorci d'Informació i Documentació de Catalunya (CIDC), actualmente Institut Català d'Estadística, el servicio de documentación del Institut Químic de Sarrià, el Centro de Documentación de Higiene y Seguridad en el Trabajo; y —mas tarde — del Institut Català de Tecnología, DOC6, el Col.legi Oficial de BibliotecarisDocumentalistes o el Institut Català de Noves Professions.

\subsection{Núcleo docente de Valencia}

Valencia, tal y como afirma Ernest Abadal, "se encontraría entre la polarización Madrid-Barcelona. Se trata de un centro de actividades que, aunque quizá no consiguió la relevancia de los dos anteriores [Madrid y Barcelona], ha desempeñado una larga y continuada tarea en pro del desarrollo de la Información y Documentación" (Abadal, 1994, p.11).

En la Facultad de Medicina de la Universidad de Valencia existe el Área de Documentación Médica, que conjuntamente con el Área de Historia de la Ciencia, han desarrollado y siguen desarrollando una gran labor docente e investigadora, impartiendo la docencia de la asignatura "Documentación Médica", así como programas de doctorado y de posgrado, en el ámbito de la documentación médica, pero también en el de la documentación general, como el caso del Curso de Posgrado de Especialista en Documentación Científica. Además, desde 1978 también se imparte esta asignatura como materia optativa en la Diplomatura de Enfermería. 
Deben reseñarse también los estudios sobre Bibliometría realizados por este grupo investigador y sus aportaciones al concepto de Documentación, así como toda su producción científica en el marco del Instituto de Estudios Documentales e Históricos sobre la Ciencia, vinculado al Consejo Superior de Investigaciones Científicas (CSIC).

Históricamente estos tres núcleos han sido los que han consolidado la Biblioteconomía y la Documentación en España, permitiendo la creación y la expansión actual de estas disciplinas, y luego ampliados y reforzados por el resto de núcleos surgidos gracias a la implantación de las Diplomaturas y Licenciaturas en otras universidades españolas.

Estos tres núcleos han dado a la investigación en Documentación un gran empuje, tanto desde el punto de vista más generalista (Universidad Complutense y Universidad de Barcelona), como desde el punto de vista más especializado, o

\begin{tabular}{|l|l|l|l|}
\hline UNIVERSIDAD & \multicolumn{1}{|c|}{ CENTRO } & \multicolumn{1}{c|}{ UNICIO } & \multicolumn{1}{|c|}{ URL } \\
\hline Barcelona & $\begin{array}{l}\text { Escde Biblioteconomía y } \\
\text { Documentación “Jordi } \\
\text { Rubió i Balaguer } \\
\text { (actualmente Facultat de } \\
\text { Biblioteconomia i } \\
\text { Documentació }\end{array}$ & 1982 & http://www.ub.es/biblio/bid \\
\hline Granada & $\begin{array}{l}\text { Fac. Biblioteconomía y } \\
\text { Documentación }\end{array}$ & 1983 & http://www.ugr.es:80/servlet/PlanServlet \\
\hline Salamanca & $\begin{array}{l}\text { Fac. Traducción e } \\
\text { Interpretación }\end{array}$ & 1987 & http://exlibris.usal.es/Programas/biblio.htm \\
\hline Murcia & $\begin{array}{l}\text { Fac. Ciencias de la } \\
\text { Documentación }\end{array}$ & 1988 & http://www.um.es/fccd/estudios.html \\
\hline Zaragoza & Fac. Filosofía y Letras & 1989 & http://wzar.unizar.es/servicios/primer/reno/26.html \\
\hline Carlos III & $\begin{array}{l}\text { Fac. Humanidades, } \\
\text { Comunicación y } \\
\text { Documentación }\end{array}$ & 1990 & http://www.uc3m.es/uc3m/dpto/BD/dpbdb01.html \\
\hline Complutense & $\begin{array}{l}\text { Esc. Biblioteconomía y } \\
\text { Documentación }\end{array}$ & 1990 & http://www.eubd.ucm.es/plan/plan.html \\
\hline León & Fac. Filosofía y Letras & 1990 & http://www.unileon.es/dp/abd/plan.htm \\
\hline Extremadura & $\begin{array}{l}\text { Fac. Biblioteconomía y } \\
\text { Documentación }\end{array}$ & 1994 & $\begin{array}{l}\text { http://alcazaba.unex.es/doc- } \\
\text { es/facultad/recursos/asignaturas/diplomatura.html }\end{array}$ \\
\hline La Coruña & Fac. Humanidades & 1996 & http://www.udc.es/planes/7102.asp \\
\hline Valencia & Fac. Informática & 1996 & http://www.uv.es/ fresquet/TEXTOS/diplo.html \\
\hline Valencia & Fac. Geografía e Historia & & \\
\hline
\end{tabular}

Tabla 2. Estudios de diplomatura en Biblioteconomía y Documentación

Scire. $7: 2$ (jul.-dic. 2001) 11-38. 
mejor dicho, aplicado a ámbitos concretos: Comunicación, Traducción e Interpretación y Ciencias Químicas en la Universidad Autónoma de Barcelona y Medicina en la Universidad de Valencia.

En 1983 y con la aprobación de la LRU, se inicia la reforma y nuevo diseño de las titulaciones universitarias, y en 1991 y 1992 se aprueban los planes de Estudios conducentes a la obtención de los títulos de Diplomado en Biblioteconomía y Documentación y Licenciado en Documentación respectivamente, dando paso a su posible implantación en las diversas universidades españolas. El panorama cambia radicalmente y en pocos años se empieza a impartir la Documentación en muchas universidades españolas.

Los estudios de Diplomatura, correspondientes al primer ciclo pero con título terminal, Diplomado en Biblioteconomía y Documentación, los encontramos en doce centros universitarios repartidos por diez comunidades autónomas (Tabla 2).

La Licenciatura en Documentación, o sea el segundo ciclo de estos estudios, que dan lugar al título de Licenciado en Documentación, se realizan en once centros universitarios repartidos por siete comunidades autónomas (Tabla 3).

\begin{tabular}{|c|c|c|c|}
\hline UNIVERSIDAD & CENTRO & INICIO & URL \\
\hline Carlos III & $\begin{array}{l}\text { Fac. Humanidades, } \\
\text { Comunicación y } \\
\text { Documentación }\end{array}$ & 1994 & http://www.uc3m.es/uc3m/dpto/BD/dpbdb01.html \\
\hline $\begin{array}{l}\text { Alcalá de } \\
\text { Henares }\end{array}$ & $\begin{array}{l}\text { Dpto. Ciencias de la } \\
\text { Computación }\end{array}$ & 1994 & http://www.cc.alcala.es/lbd.htm \\
\hline Granada & $\begin{array}{l}\text { Fac. Biblioteconomía y } \\
\text { Documentación }\end{array}$ & 1994 & http://www.ugr.es:80/servlet/PlanServlet \\
\hline Salamanca & $\begin{array}{l}\text { Fac. Traducción e } \\
\text { Interpretación }\end{array}$ & 1994 & http://exlibris.usal.es/Programas/docu.htm \\
\hline Complutense & $\begin{array}{l}\text { Esc. Biblioteconomía y } \\
\text { Documentación }\end{array}$ & 1996 & $\begin{array}{l}\text { http://www.ucm.es/info/INFOCOM/estudios/planes/ } \\
\text { document.htm }\end{array}$ \\
\hline Extremadura & $\begin{array}{l}\text { Fac. Biblioteconomía y } \\
\text { Documentación }\end{array}$ & 1997 & $\begin{array}{l}\text { http://alcazaba.unex.es/doc- } \\
\text { es/facultad/recursos/asignaturas/diplomatura.html }\end{array}$ \\
\hline $\begin{array}{l}\text { Politécnica de } \\
\text { Valencia }\end{array}$ & Fac. Informática & 1997 & http://infoserver.upv.es/pla/i_tit2/65/index.html \\
\hline Barcelona & $\begin{array}{l}\text { Fac. de Ciencias de la } \\
\text { Documentación }\end{array}$ & 1998 & http://www.ub.es/biblio/bid \\
\hline Murcia & $\begin{array}{l}\text { Fac. Ciencias de la } \\
\text { Documentación }\end{array}$ & 1998 & http://www.um.es/fccd/estudios.html \\
\hline $\begin{array}{l}\text { Autónoma de } \\
\text { Barcelona }\end{array}$ & $\begin{array}{l}\text { Fac. Ciencias de la } \\
\text { Comunicación }\end{array}$ & 1999 & http://www.uab.es/fac-ciencies-comunicació \\
\hline $\begin{array}{l}\text { Oberta de } \\
\text { Catalunya }\end{array}$ & $\begin{array}{l}\text { Estudis de } \\
\text { Documentació }\end{array}$ & 1999 & http://www.uoc.es \\
\hline
\end{tabular}

Tabla 3. Estudios de Licenciatura en Documentación en España (Universidades Públicas)

Scire. $7: 2$ (jul.-dic. 2001) 11-38. 


\begin{tabular}{|c|c|c|}
\hline UNIVERSIDAD & PROGRAMA & URL \\
\hline $\begin{array}{l}\text { Alcalá de } \\
\text { Henares }\end{array}$ & $\begin{array}{l}\text { Documentación, Información y } \\
\text { conocimiento }\end{array}$ & http://www.cc.alcala.es/Cursos.htm \\
\hline Barcelona & $\begin{array}{l}\text { Documents i sistemes documentals } \\
\text { en l'entorn digital }\end{array}$ & http://www.ub.es/udbd \\
\hline Carlos III & Documentación & $\begin{array}{l}\text { http://www.uc3m.es/uc3m/gral/TC/ESDO/ } \\
\text { esdo03.html }\end{array}$ \\
\hline Complutense & $\begin{array}{l}\text { Aspectos teóricos, históricos, } \\
\text { tecnológicos y aplicaciones de la } \\
\text { documentación informativa }\end{array}$ & http://wwwmeta.sim.ucm.es/vax/1570098013.HTM \\
\hline Granada & $\begin{array}{l}\text { Documentación e Información } \\
\text { Científica }\end{array}$ & http://www.ugr.es:80/servlet/PlanServlet \\
\hline Murcia & $\begin{array}{l}\text { Técnicas y métodos actuales en } \\
\text { Información y Documentación }\end{array}$ & $\begin{array}{l}\text { http://www.um.es/siu/inves/doctorado/97-99/ } \\
\text { documentación.htm }\end{array}$ \\
\hline Salamanca & $\begin{array}{l}\text { Metodología y líneas de investigación } \\
\text { en Biblioteconomía y Documentación }\end{array}$ & http://exlibris.usal.es/Tciclo/D9799.htm \\
\hline $\begin{array}{l}\text { Politécnica de } \\
\text { Valencia }\end{array}$ & Documentación & Facultad de Informática \\
\hline Valencia & Documentación & http://www.uv.es/ frequest/TEXTOS/doc97.html \\
\hline Zaragoza * & $\begin{array}{l}\text { Sistemas de Información y } \\
\text { Documentación }\end{array}$ & $\begin{array}{l}\text { http://wzar.unizar.es/servicios/ciclo3/prog/ } \\
\text { H121.HTML }\end{array}$ \\
\hline
\end{tabular}

* La Universidad de Zaragoza oferta un doctorado en este campo, en el marco de la Facultad de Filosofía y Letras, aunque no dispone de la licenciatura en Documentación.

Tabla 4. Estudios de Tercer Ciclo en Documentación en España

Por lo que respecta a los terceros ciclos, que son los que mejor acogen las tendencias investigadoras, puesto que los doctorados son los que permiten la formación de los futuros investigadores, el panorama se refleja en la tabla 4.

\subsection{Otros núcleos docentes}

Ya se ha visto anteriormente que tanto Madrid como Barcelona fueron en 1971 las pioneras en cursar la asignatura Documentación dentro de los estudios en Ciencias de la Información. Aunque no de manera exhaustiva, pero útil para enmarcar otros núcleos o grupos de formación y por tanto también de investigación, se pueden reseñar otras universidades españolas con facultades que tienen en sus planes de estudios, asignaturas del ámbito de la Biblioteconomía y la Documentación (Tabla 5), ya sean troncales, obligatorias de universidad u optativas. Ello ha permitido que en algunas de estas facultades se hayan creado grupos de investigación en documentación aplicada a distintos ámbitos: documentación informativa y/o periodística o documentación en comunicación, documentación médica o en ciencias de la salud, documentación química, documentación administrativa, etc. 


\begin{tabular}{|c|c|c|c|}
\hline ÁMBITO & $\begin{array}{l}\text { FACULTAD } \\
\text { DEPARTAMENTO O } \\
\text { INSTITUTO }\end{array}$ & UNIVERSIDAD & ASIGNATURA \\
\hline \multirow{5}{*}{$\begin{array}{l}\text { COMUNICACIÓN } \\
\text { Periodismo } \\
\text { Comunicación } \\
\text { Audiovisual } \\
\text { Publicidad y } \\
\text { Relaciones Públicas }\end{array}$} & Ciencias Información & $\begin{array}{l}\text { Complutense / La } \\
\text { Laguna / Sevilla / } \\
\text { Santiago }\end{array}$ & $\begin{array}{l}\text { Documentación } \\
\text { Informativa o } \\
\text { Documentación }\end{array}$ \\
\hline & $\begin{array}{l}\text { Ciencias Sociales y de la } \\
\text { Información }\end{array}$ & País Vasco (Bilbao) & Periodística \\
\hline & $\begin{array}{l}\text { Humanidades, Comunicación } \\
\text { y Documentación }\end{array}$ & Carlos III de Madrid & \\
\hline & $\begin{array}{l}\text { Periodismo } \\
\text { Comunicación Audiovisual } \\
\text { Ciencias sociales }\end{array}$ & $\begin{array}{l}\text { Pompeu Fabra } \\
\text { Pompeu Fabra / } \\
\text { Málaga / Valencia } \\
\text { Salamanca / Vigo }\end{array}$ & $\begin{array}{l}\text { Tecnologías de la } \\
\text { información } \\
\text { Documentación en los } \\
\text { medios de comunicación }\end{array}$ \\
\hline & Ciencias Comunicación & $\begin{array}{l}\text { Autónoma Barcelona / } \\
\text { Málaga }\end{array}$ & $\begin{array}{l}\text { Informática Documental y } \\
\text { Teledocumentación }\end{array}$ \\
\hline \multirow[t]{6}{*}{$\begin{array}{l}\text { TRADUCCIÓN E } \\
\text { INTERPRETACIÓN }\end{array}$} & Traducción e Interpretación & $\begin{array}{l}\text { Alicante / Autónoma } \\
\text { Barcelona / Málaga / } \\
\text { Las Palmas / Valladolid } \\
\text { (Campus de Soria }\end{array}$ & $\begin{array}{l}\text { Documentación aplicada } \\
\text { a la Traducción }\end{array}$ \\
\hline & $\begin{array}{l}\text { Ciencias Humanas y } \\
\text { Sociales }\end{array}$ & Jaume I de Castelló & \\
\hline & Traductores e Intérpretes & Granada & \\
\hline & Traducción y Documentación & Salamanca & \\
\hline & $\begin{array}{l}\text { Humanidades, Filología y } \\
\text { Traducción }\end{array}$ & Vigo & \\
\hline & $\begin{array}{l}\text { Filología, Instituto } \\
\text { universitario de Lenguas } \\
\text { Modernas }\end{array}$ & Complutense & \\
\hline MEDICINA & $\begin{array}{l}\text { Medicina } \\
\text { Diplomatura de Enfermería }\end{array}$ & $\begin{array}{l}\text { Valencia / Murcia } \\
\text { Valencia }\end{array}$ & $\begin{array}{l}\text { Introducción a la } \\
\text { Medicina y metodología } \\
\text { científica }\end{array}$ \\
\hline \multirow[t]{2}{*}{ QUIMICAS } & Dpto. De Químicas & Autónoma Madrid & $\begin{array}{l}\text { Información y } \\
\text { Documentación científica }\end{array}$ \\
\hline & Ciencias & Autónoma Barcelona & Documentación Química \\
\hline \multirow{4}{*}{$\begin{array}{l}\text { CIENCIAS } \\
\text { HUMANAS Y } \\
\text { SOCIALES }\end{array}$} & Filosofía & Complutense & Bibliografía \\
\hline & Geografía e Historia & $\begin{array}{l}\text { Granada / Salamanca / } \\
\text { Santiago }\end{array}$ & $\begin{array}{l}\text { Archivística y } \\
\text { Biblioteconomía }\end{array}$ \\
\hline & Humanidades & Autónoma Barcelona & $\begin{array}{l}\text { Técnicas de } \\
\text { documentación y } \\
\text { Archivística }\end{array}$ \\
\hline & Historia & Barcelona & \\
\hline
\end{tabular}

Tabla 5. Asignaturas del ámbito de la Biblioteconomía y la Documentación en planes de estudios de facultades distintas a las de Documentación

Scire. $7: 2$ (jul.-dic. 2001) 11-38. 


\section{Posgrados, Másteres y otros cursos de formación}

También se pueden destacar, aunque tengan un carácter más profesional y de formación, los distintos cursos de posgrado y máster, que también han proliferado en los últimos años, y que nos dan idea también de las necesidades formativas o de especialización de los diplomados y licenciados en Documentación, pero también de otras ramas y de los profesionales en general. Todo ello puede también dar pistas sobre el tipo de investigación necesaria. Los que están reconocidos por las propias universidades o por organismos e instituciones de prestigio se enumeran en la tabla 6.

La mayoría de posgrados y másteres presentados, o bien son generales, o bien se especializan en un ámbito concreto - Archivística, medicina, empresa, gestión-. Todos ellos tienen una gran carga tecnológica.

En un estudio realizado por profesores de la Universidad Carlos III de Madrid (Caridad et al, 1999, p. 241) sobre el tipo de cursos cortos realizados entre febrero de 1998 y octubre de 1999, impartidos mayoritariamente por instituciones o empresas privadas, se observa que fundamentalmente la temática de los cursos se centra en tecnología, análisis documental y gestión. (Fig. 2)

Ya hemos visto que hasta principios de los ochenta los tres núcleos docentes - Madrid, Barcelona y Valencia- conjuntamente con algunas asociaciones y organismos de prestigio, son los que aglutinan la formación y también la investigación, generalista pero también aplicada, sobre todo en los campos de la Medicina, la Química y la Comunicación. Con la introducción de las diplomaturas (principios de los años ochenta) y las licenciaturas (principios de los noventa) en otras universidades el campo se amplía, sobretodo con las últimas, puesto que son las que van

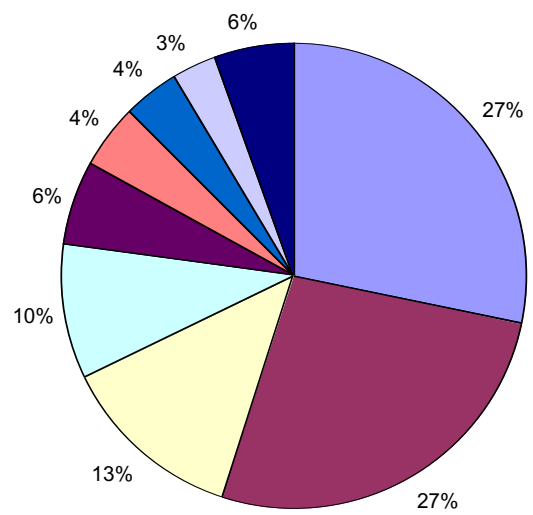

$\square$ Tecnologías

$\square$ Análisis

$\square$ Gestión

$\square$ Inf. Especializada (29)

$\square$ Referencia

$\square$ Doc. gral

$\square$ Usuarios

$\square$ Archivos

Otros

Figura 2. Número de cursos sobre Documentación ofrecidos entre enero de 1998 y octubre de 1999, por tipo de curso

Scire. $7: 2$ (jul.-dic. 2001) 11-38. 


\begin{tabular}{|c|c|c|}
\hline TIEMPO & TITULO DEL CURSO & ORGANISMO O INSTITUCIÓN \\
\hline \multirow[t]{2}{*}{$\begin{array}{l}400-600 \mathrm{~h} \\
1 \text { o } 2 \text { cursos }\end{array}$} & \multirow[t]{2}{*}{ Máster en Información y Documentación } & $\begin{array}{l}\text { Universidad Carlos III-Dept. Biblioteconomía } \\
\text { y Documentación }\end{array}$ \\
\hline & & $\begin{array}{l}\text { Universidad de Sevilla-Dpt de Comunicación } \\
\text { y Instituto Andaluz del Patrimonio Histórico }\end{array}$ \\
\hline \multirow[t]{2}{*}{$\begin{array}{l}250-500 \mathrm{~h} \\
1 \text { o } 2 \text { cursos }\end{array}$} & \multirow[t]{2}{*}{ Máster de archivística } & $\begin{array}{l}\text { Universidad de Sevilla-Dpt de Historia } \\
\text { medieval y Instituto Andaluz del Patrimonio } \\
\text { Histórico }\end{array}$ \\
\hline & & $\begin{array}{l}\text { Universitat Autònoma de Barcelona-Dpt de } \\
\text { Ciències de L'antiguitat i de l' Edad Mitjana y } \\
\text { Associació d'Archivers de Catalunya }\end{array}$ \\
\hline \multirow[t]{3}{*}{$\begin{array}{l}400-700 h \\
2 \text { cursos }\end{array}$} & \multirow[t]{2}{*}{$\begin{array}{l}\text { @Máster de especialidad en } \\
\text { Documentación Médica }\end{array}$} & $\begin{array}{l}\text { Universidad de Valencia-Instituto de Estudios } \\
\text { Documentales e Históricos sobre Ciencia } \\
\text { (CSIC) }\end{array}$ \\
\hline & & $\begin{array}{l}\text { Universitat Autònoma de Barcelona- Dpt. De } \\
\text { Documentació de l'Hospital de la Sta.Creu i } \\
\text { Sant Pau- Àrea de Documentació }\end{array}$ \\
\hline & $\begin{array}{l}\text { Máster en Documentación y Sistemas } \\
\text { de Información Sanitaria }\end{array}$ & $\begin{array}{l}\text { Universidad Complutense de Madrid- } \\
\text { Facultad de Medicina }\end{array}$ \\
\hline $150-300 \mathrm{~h}$ & $\begin{array}{l}\text { Organización, acceso y recuperación de } \\
\text { información electrónica en } \\
\text { Biblioteconomia y Documentación }\end{array}$ & $\begin{array}{l}\text { Universidad de Valencia-Instituto de Estudios } \\
\text { Documentales e Históricos sobre Ciencia } \\
\text { (CSIC) }\end{array}$ \\
\hline \multirow[t]{6}{*}{$\begin{array}{l}100-200 \mathrm{~h} . \\
6 \text { a } 12 \text { meses }\end{array}$} & $\begin{array}{l}\text { Especialista Universitario en } \\
\text { Documentación }\end{array}$ & $\begin{array}{l}\text { Universidad Complutense de Madrid-Dpt.de } \\
\text { Biblioteconmía y Documentación }\end{array}$ \\
\hline & $\begin{array}{l}\text { Distintos postgrados relacionados con la } \\
\text { Documentación (tecnologia, empresa, } \\
\text { fuentes de información, gestión) }\end{array}$ & $\begin{array}{l}\text { Universitat Pompeu Fabra-IDEC Institut de } \\
\text { Formació Continuada }\end{array}$ \\
\hline & Postgrau en Documentació digital & $\begin{array}{l}\text { Universitat Pompeu Fabra-Dpt de Ciencias } \\
\text { Polítiques y Socials, Secció de } \\
\text { Biblioteconomia y Documentació }\end{array}$ \\
\hline & $\begin{array}{l}\text { Postgrado en Organización de sistemas } \\
\text { de documentación en la empresa }\end{array}$ & $\begin{array}{l}\text { Universitat de Barcelona- Dpt de } \\
\text { Biblioteconomía y Documentación }\end{array}$ \\
\hline & Postgrado en Biblioteca Escolar & Universitat Politècnica de Catalunya \\
\hline & $\begin{array}{l}\text { Postgrau en noves tecnologies per a la } \\
\text { gestió i l'accés a la informació } \\
\text { Postgrau en organització dels sistemes } \\
\text { d'informació en l'empresa } \\
\text { Postgrau en gestió de serveis } \\
\text { d'informació i biblioteques digitals } \\
\text { Certificat universitari de Tècniques } \\
\text { Documentals (Itinerari de campus) }\end{array}$ & $\begin{array}{l}\text { Universitat Autònoma de Barcelona-Àrea de } \\
\text { Documentació }\end{array}$ \\
\hline
\end{tabular}


a permitir la puesta en marcha de los doctorados específicos en Documentación. Hasta este momento estos se habían realizado en departamentos de otras facultades $\mathrm{y}$, por lo tanto, las tesis doctorales se habían presentado y leído en ellos, con lo que la investigación en Información y Documentación quedaba dispersa entre departamentos de facultades distintas y centros públicos y privados de investigación, como por ejemplo el CINDOC, como se verá posteriormente.

\section{Proyectos de investigación subvencionados}

Se han estudiado dos períodos, 1975-1990 y 1990-1999, a partir de la interpretación y evaluación de los resultados aportados por las investigaciones llevadas a cabo por distintos autores (Roman-Sorli, 1990, p. 1171-1185; Abellán-SerranoErnica, 1997, p.49 ss.; Solano-López, 1998, p. 855-870). Estos datos se han complementado con nuestra propia investigación y rastreo de los distintos proyectos financiados con fondos públicos, realizados o en curso de realización, que se recogen en la base de datos PROY elaborada por el Consejo General de Universidades.

Con todo ello, se ha podido marcar la evolución de los proyectos de investigación en Información y Documentación en los períodos antes reseñados. Para llevar a cabo esta tarea hemos agrupado los distintos proyectos en cinco áreas generales de investigación:

- Estudios bibliométricos: Se incluyen los proyectos que tienen como objetivo el enriquecimiento del conocimiento de la producción científica en múltiples ámbitos de actividad.

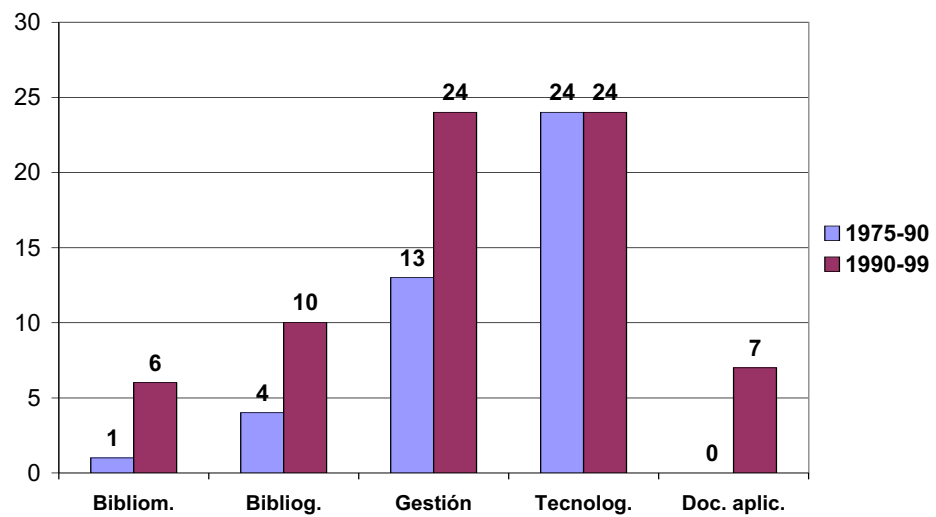

Figura 3. Evolución del número de proyectos y su distribución en áreas de investigación durante los períodos 1975-90 y 1990-99

Scire. $7: 2$ (jul.-dic. 2001) 11-38. 
- Estudios bibliográficos: Se incluyen los proyectos dedicados a estudiar, inventariar o catalogar fondos bibliográficos ya existentes.

- Gestión y evaluación de sistemas de información: Se engloban los proyectos que tratan sobre sistemas bibliotecarios, documentales y archivísticos; así mismo, aquellos estudios sobre estos tipos de unidades de información desde un punto de vista histórico. También se han incluido aquellos otros proyectos que se han orientado a desarrollar aspectos afines a la gestión de sistemas de información.

- Tecnologías de la información: Se han distinguido dos vertientes. Por un lado proyectos orientados al desarrollo de aplicaciones tecnológicas, y por el otro, los estudios y análisis sobre diversos aspectos relacionados con las tecnologías de la información como la automatización de centros,la información electrónica, el diseño de bases de datos, las redes, etc.

- Documentación aplicada: Se inscriben aquí los proyectos en los que se estudia la aplicación de las técnicas y procesos documentales en ámbitos de actividad concretos: ciencia y tecnología, ciencias médicas y de la salud, ciencias de la comunicación, ciencias humanas y sociales, etc.

La evolución cuantitativa y su distribución en las cinco áreas propuestas se recoge en la tabla 7 (en la página siguiente) y la figura 3. Se observa un incremento general en el último período analizado. Destaca el aumento de los proyectos en el área de gestión, el mantenimiento del ritmo en los de ámbito tecnológico y llama la atención el significativo crecimiento de los proyectos en los que cobra protagonismo la aplicación práctica de la Documentación. Estas tendencias se reflejan de forma gráfica en la figura 3.

Se observa también que los centros participantes en los proyectos de investigación forman dos grupos bien definidos. Por una lado, los centros universitarios, entre los que destacan la Universidad Complutense, y la Universidad Autónoma de Barcelona; y, por el otro, centros no universitarios, entre los que cabe señalar CINDOC y la Biblioteca Nacional. Cada vez es más usual la cooperación entre ambos tipos de centros, por lo que respecta a la realización de los proyectos. Se constata también la incipiente participación de las empresas privadas en proyectos conjuntos con las universidades españolas.

\section{La literatura científica en Información y Documentación}

A la hora de examinar la situación actual de la producción científica en el ámbito de la Información y la Documentación nos hemos limitado a esbozar una panorámica descriptiva que incluye tanto la literatura científica (monografías, tesis doctorales y publicaciones periódicas) como las reuniones científicas (con- 
gresos, jornadas, seminarios, etc.) que de forma regular o esporádica se llevan a cabo a lo largo y ancho de la geografía del Estado español.

Utilizamos la denominación "Información y Documentación” desde un punto de vista omnicomprensivo, quiere esto decir que bajo tal denominación se han incluido referencias a todos los trabajos de investigación dedicados a disciplinas como la Archivística, la Biblioteconomía o la Documentación, o que se hayan ocupado de la gestión de cualquier tipología de unidad de información, o incluso de aspectos afines a ellas.

De cada uno de los ámbitos estudiados se ha intentado recabar la información con una pretensión exhaustiva. Para ello se ha recurrido a diversas fuentes. La principal ha sido la Bibliografía española, complementada con la consulta del catálogo bibliográfico ISBN. Para el conocimiento de las tesis doctorales se ha accedido a la base de datos TESEO. Junto a estas fuentes bibliográficas básicas se han manejado dos trabajos que han aportado una información esencial para conocer le evolución de la producción científica en nuestro ámbito de estudio. Nos estamos refiriendo a la obra de Ernest Abadal La Documentación en España y al estudio de Amadeu Pons Aproximació a una bibliografia espanyola en biblioteconomia i documentació (1990-1995).

\subsection{Monografías}

El período revisado para este tipo de trabajos es el que va desde 1980 a 1999. En este lapso de tiempo se han publicado 320 monografías. En la figura 4, que muestra la distribución cuantitativa entre ambas décadas, se observa en los años 90 un incremento de casi un 100\% respecto a la década precedente. Este dato, ya de por sí elocuente sobre el crecimiento de la producción bibliográfica, debe ser matizado y complementado por otras informaciones.

La evolución en cuanto al número de monografías publicadas es aún más espectacular si tomamos como referencia los datos que aporta Abadal (1994, p. 92) para las monografías del ámbito estrictamente biblioteconómico-documental desde la década de los setenta. En ese caso, como muestra la figura 5 el número de trabajos hasta 1999 se ha multiplicado por 13, de la docena de monografías contabilizadas a finales de los setenta se ha pasado a más de 160 publicadas durante la década de los noventa.

La significación del volumen de monografías publicadas debe matizarse atendiendo a los datos relativos a su nivel de especialización. Una parte considerable de la producción bibliográfica revisada corresponde todavía a manuales que abordan sus contenidos de forma muy general y divulgativa. Pese a ello, en los últimos años se detecta una progresiva especialización temática que han incidido primordialmente en cuatro ámbitos: 


\begin{tabular}{|l|c|c|}
\hline Areas & $\mathbf{1 9 7 5 - 9 0}$ & $\mathbf{1 9 9 0 - 9 9}$ \\
\hline Bibliometría & 1 & 6 \\
\hline Bibliografía & 4 & 10 \\
\hline Gestión & 13 & 24 \\
\hline Tecnologías: & 24 & 24 \\
- Aplicaciones & 15 & 14 \\
- Estudios y análisis & 9 & 10 \\
\hline Documentación aplicada & 0 & 7 \\
\hline Total & $\mathbf{4 2}$ & $\mathbf{7 1}$ \\
\hline
\end{tabular}

Tabla 7. Areas de investigación

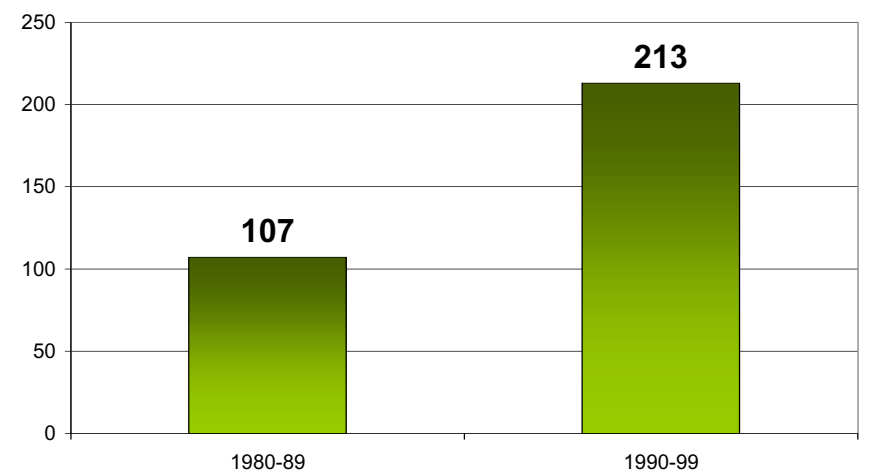

Figura 4. Monografías sobre información y documentación publicadas durante el período 1980-1999

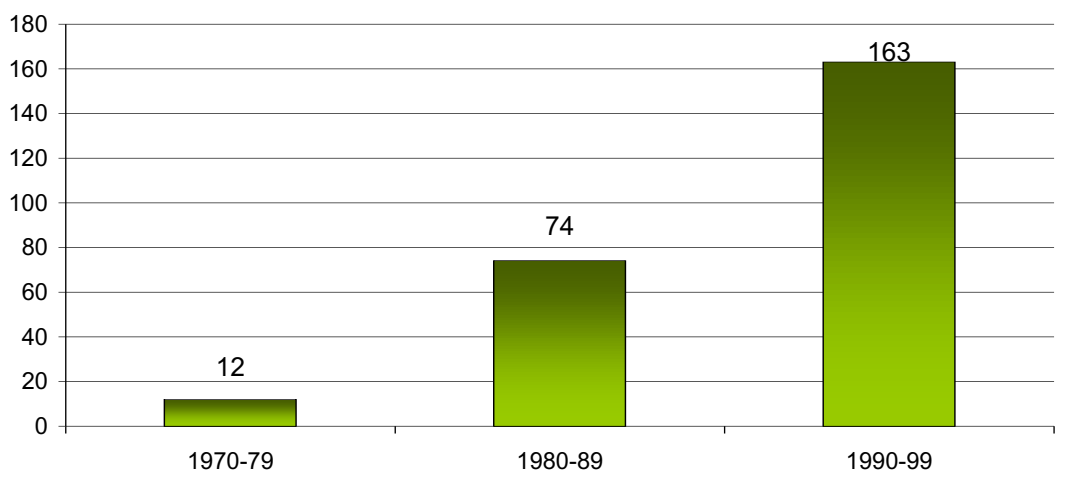

Figura 5. Monografías sobre biblioteconomía y documentación publicadas entre 1970-1999

Scire. $7: 2$ (jul.-dic. 2001) 11-38. 
- Gestión de unidades de información

- Lingüística documental

- Fuentes de información especializada

- Aplicación de las tecnologías de la información en el entorno biblioteconómico y documental.

El aumento en la producción bibliográfica que Abadal presagiaba en 1994 se ha consumado, y las razones básicas que este autor aducía continúan vigentes: la creación de nuevas Escuelas y Facultades de Documentación, la introducción de la Documentación como materia en diversos planes de estudio, y el consiguiente crecimiento en el número de alumnos, docentes e investigadores han multiplicado tanto la cifra de lectores como de autores. Junto a estos factores, en la actualidad se pueden aportar otros complementarios que justifican el proceso de consolidación de un mercado editorial: el incremento del número de profesionales en ejercicio que demandan instrumentos para su reciclaje formativo, y una percepción social cada vez más sensible a la importancia de la gestión de la información en la práctica totalidad de ámbitos de actividad.

El aumento en la producción bibliográfica se ha traducido lógicamente en la aparición de sellos editoriales que se han dedicado a la publicación de este tipo de materiales. Junto a la desaparecida Mitre, hoy destacan las madrileñas Síntesis, Pirámide y Paraninfo, así como la asturiana Trea. Existen muchas otras que de forma ocasional han publicado algún libro sobre el tema. Cabe reseñar también el papel desarrollado por instituciones que no son propiamente editoriales como FUINCA, el Centre d'Investigació de la Comunicació en Catalunya y, sobre todo, los centros universitarios. La Universidad Complutense de Madrid y las Universidades de Murcia, Granada y Valencia son las que más títulos han publicado. Estas dos últimas disponen de colecciones específicas, quizá el mejor ejemplo lo constituyan los "Cuadernos de Documentación e Informática Biomédica", vinculados a la Facultad de Medicina de la Universidad de Valencia. Existen otras colecciones, ya clásicas en el ámbito biblioteconómico, como la "Biblioteca del libro" de la Fundación Germán Sánchez Ruipérez.

\subsection{Tesis doctorales}

Una aproximación cuantitativa a la evolución de las tesis doctorales sobre Información y Documentación revela un crecimiento espectacular desde la segunda mitad de los años ochenta, tal y como muestra la figura 6.

Nuevamente la información cuantitativa debe ser matizada. De las 143 tesis doctorales contabilizadas hasta 1997 (la base de datos Teseo está actualizada hasta esa fecha) cerca de un $60 \%$ son tesis bibliométricas o bibliográficas; es decir, tesis en las que la dimensión instrumental o auxiliar de disciplinas como la Bibliometría 


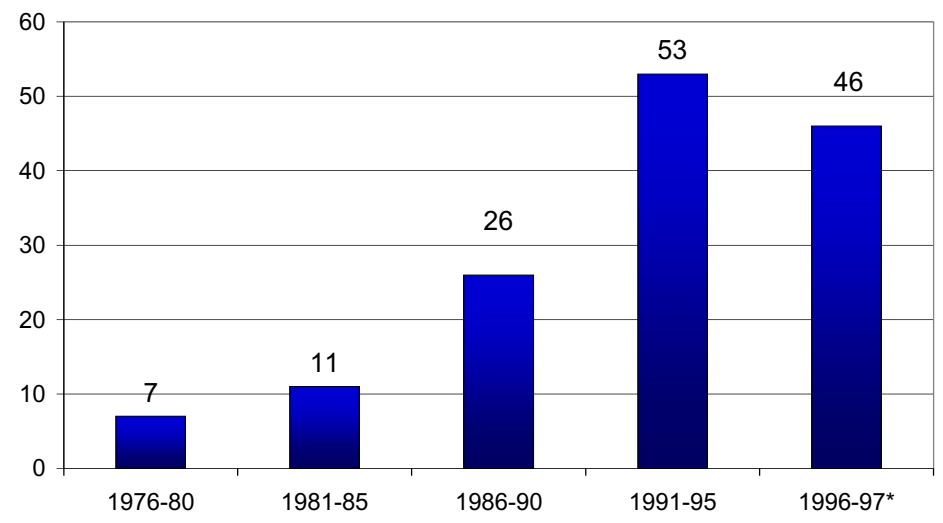

Figura 6. Tesis doctorales leídas entre 1976 y 1997

o la Bibliografía no constituyen el ámbito de investigación, sino meras técnicas para la exploración de la producción científica en un ámbito determinado. Las tesis bibliométricas se han desarrollado tradicionalmente en facultades vinculadas a las ciencias biomédicas. La más prolífica en este ámbito ha sido la Facultad de Medicina de la Universidad de Valencia a través de su Cátedra de Documentación Médica. Por lo que respecta a las tesis bibliográficas, éstas se han defendido normalmente en facultades humanísticas, cuyo mejor ejemplo es la Universidad Complutense de Madrid, a través de su Facultad de Filosofía y Letras.
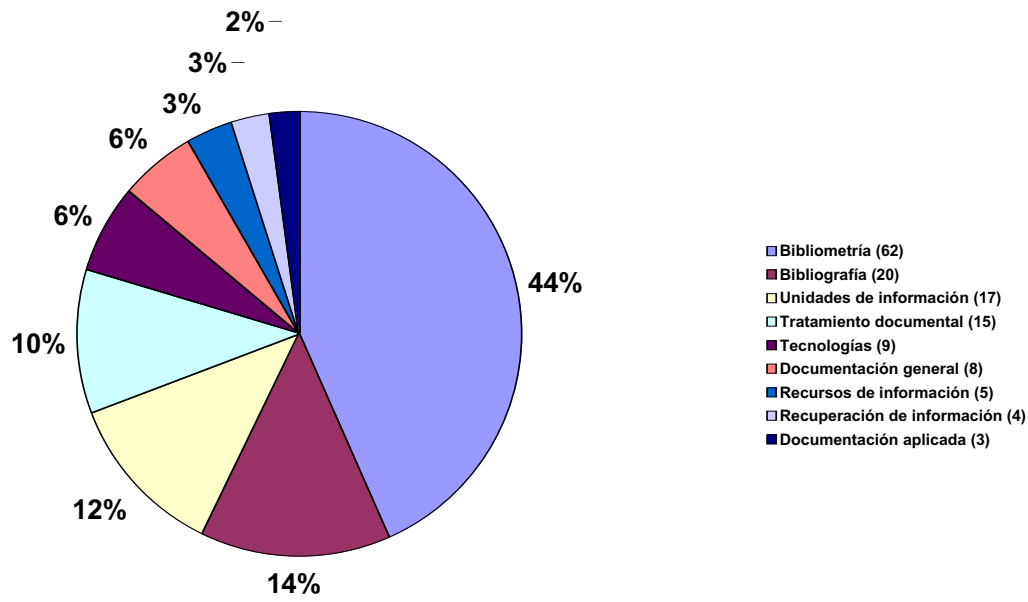

Figura 7. Ámbitos de investigación en las tesis doctorales

Scire. $7: 2$ (jul.-dic. 2001) 11-38. 
Hasta mediados de los años noventa no comienzan a surgir los primeros doctorados en Biblioteconomía y Documentación en el Estado español. Por esta razón, la mayoría de tesis doctorales vinculadas al ámbito de la Información y Documentación se han defendido en departamentos muy diversos, no sólo por su ubicación geográfica, sino también por las áreas de conocimiento que han representado, hechos que han contribuido a su dispersión.

Si bien es cierto que el mayor número de tesis defendidas en los últimos años continúan correspondiendo a investigaciones bibliométricas, progresivamente y como muestra la figura 7, se están llevando a cabo trabajos de investigación en otros ámbitos, entre los que destacan: el diseño y gestión de unidades de información (existe un nutrido número de tesis doctorales centradas en bibliotecas escolares), el tratamiento documental y la aplicación de las tecnologías a la documentación. Es significativa la escasa atención dedicada a la documentación aplicada, donde existen interesantísimas áreas de investigación por explorar.

\subsection{Publicaciones periódicas}

Las revistas decanas en el ámbito de la Información y la Documentación se han de situar en el entorno de las primeras asociaciones profesionales, núcleos de formación y bibliófilos. Así, la centenaria Revista de archivos, bibliotecas y museos, surgida en 1871 y desaparecida en 1978 era responsabilidad del Cuerpo Facultativo de Archiveros, Bibliotecarios y Arqueólogos; Quaderns d'estudi, de trayectoria mucho más breve (1915-1922) fue editada por la Escola de Bibliotecàries de Barcelona, mientras que el Boletín de bibliotecas y bibliografía, de vida efímera (1934-35) como la mayoría de publicaciones sobre bibliofilia en España, la publicaba en Madrid la Asociación de Bibliotecarios y Bibliófilos Españoles.

Desde 1871 hasta el día de hoy se contabilizan alrededor de sesenta publicaciones periódicas especializadas en el triple ámbito de la Archivística, Biblioteconomía y Documentación. Pese a que la nómina pueda parecer extensa, la coincidencia en el tiempo de las diversas publicaciones nunca ha sido numerosa como muestra la figura 8. En la actualidad se pueden encontrar en el mercado treinta y dos publicaciones. La periodicidad, enfoque y alcance temático hace de esta oferta bibliográfica algo muy heterogéneo.

En cuanto a la responsabilidad editorial, los datos que ofrece la figura 9 demuestran que más del $60 \%$ de las publicaciones son editadas por asociaciones profesionales o centros docentes universitarios. La presencia de editoriales privadas es todavía muy reducida en este sector. Con la aparición de Information world en español (1992-1997), hoy El profesional de la información (1997-), entró en el mercado español de las revistas de Información y Documentación el primer editor privado. Tras Learned information en 1992 se han incoporado otras dos empresas que publican Bibliofórum (1995-) y la desaparecida Revista de telemática e infor- 


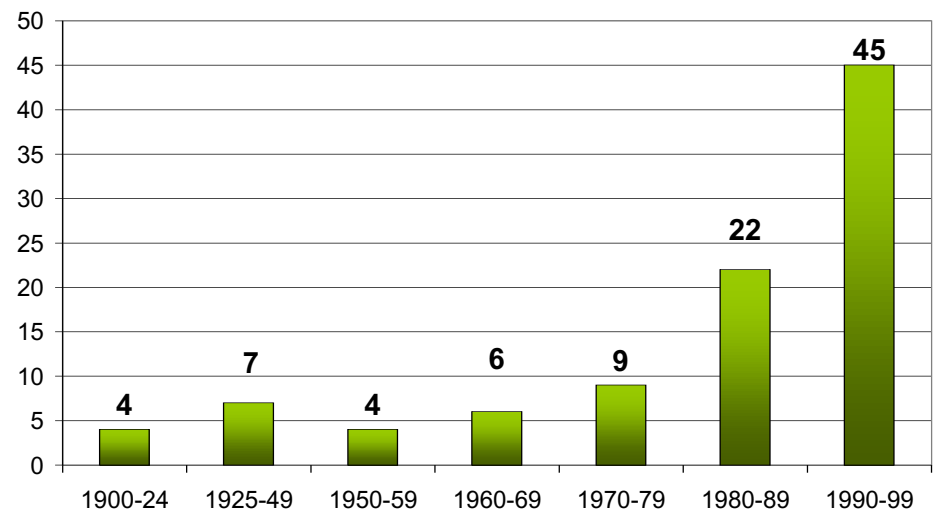

Figura 8. Publicaciones periódicas vivas entre 1900 y 1999

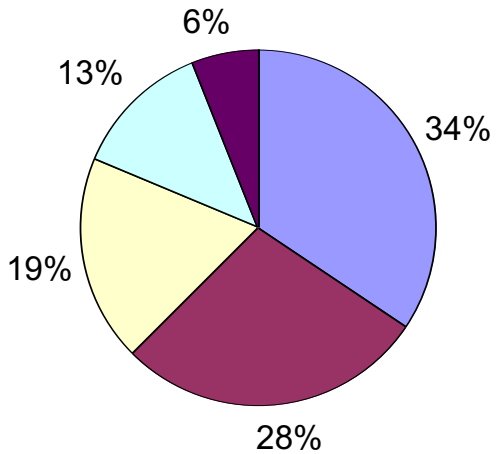

$\square$ Asociaciones profesionales (11)

Figura 9. Editores de revistas

\begin{tabular}{|c|c|c|}
\hline Periodicidad & Número & $\%$ \\
\hline Anual & 10 & 31 \\
\hline Semestral & 7 & 22 \\
\hline Trimestral & 6 & 19 \\
\hline Irregular & 4 & 13 \\
\hline Mensual & 3 & 9 \\
\hline Bimestral & 1 & 3 \\
\hline
\end{tabular}

Tabla 8. Periodicidad de las revistas de Información y documentación

Scire. $7: 2$ (jul.-dic. 2001) 11-38. 
mación (1994-1998). También la empresa de servicios DOC6 comenzó a publicar en 1992 Nexo, un boletín con novedades sobre el sector.

Como recoge la tabla 8 , la periodicidad de este tipo de revistas es, por lo general, muy dilatada en el tiempo. Tan sólo tres publicaciones son de periodicidad mensual: El profesional de la información, Educación y bibliotecas y Correo bibliotecario. Este dato tiene que ponerse en relación con el número total de revistas existentes para evaluar el nivel de actualización de los contenidos que ofrecen a sus lectores.

En cuanto a su nivel de especialización, de las treinta y dos revistas existentes en la actualidad cinco se adscriben al ámbito de los archivos o la Archivística, como la catalana Lligall (1988-), o Tabula: revista de Archivos de Castilla y León (1992-); otras cinco se ocupan exclusivamente del mundo bibliotecario, como por ejemplo el Boletín de la Asociación Andaluza de Bibliotecarios (1984-) o Biblos (1999-); diez publicaciones se centran en el ámbito documental, como la valenciana Métodos de información (1994-); las doce restantes corresponden a revistas que reflejan tanto la integración de las tres disciplinas - Boletín de ANABAD (1978-) y Boletín de AABADOM (1990-)— como de la Biblioteconomía y la Documentación -Item (1987-) o Anales de Documentación (1998-).

Al margen de esta adscripción por disciplinas destaca la poca especialización temática de las publicaciones periódicas españolas, muy lejos de lo que sucede en otros países, donde junto a revistas de carácter generalista es posible encontrar publicaciones altamente especializadas, algunas de ellas dedicadas a informática documental, lenguajes documentales, etc. Una tímida excepción a esta tónica general la constituyen revistas como Educación y biblioteca, Scire, Cuadernos de documentación multimedia y Papeles médicos. Por otro lado, la ausencia de revistas especializadas en ciertas áreas, por ejemplo en informática documental o Internet, está forzando a los profesionales españoles a incluir en su bibliografía de consulta prensa periódica especializada en tecnologías como PC World, Boletín de Red Iris, I-world, etc.

El objetivo de esta contribución no incluía evaluar el impacto que las revistas españolas tiene en la labor de investigadores nacionales y extranjeros. Se escapa a las posibilidades que nos habíamos propuesto. Sin embargo,una simple revisión de la presencia de las revistas españolas en la base de datos LISA puede ser un punto de referencia significativo. De las más de sesenta publicaciones españolas, un reducidísimo número se indiza: Revista Española de Documentación Científica, Scire, Boletín de la Anabad, Item y El profesional de la información son las revistas con un mayor volumen de números indizados en la referida base de datos.

Finalmente, conviene a dedicar una atención especial a las nuevas revistas electrónicas sobre Información y Documentación, que tienen ya una presencia 
real en Internet. De las treinta y dos publicaciones reseñadas, en la actualidad sólo cuatro son consultables en la red, y otras tantas disponen de una versión electrónica de sus homónimas impresas. La gratuidad de su consulta no es el único atractivo. La hipertextualidad y la interactividad aplicadas a la gestión de las publicaciones periódicas las transforma en instrumentos de una altísimo valor informativo gracias, por ejemplo, a la posibilidad de consultar sus hemerotecas digitales, o bien por el valor añadido que pueden ofrecer a través de la elaboración de directorios selectivos de recursos de información especializada. De este último caso un buen ejemplo lo constituye la revista Palimpsesto: revista electrónica de Información y Documentación publicada por la Escuela de Biblioteconomía y Documentación de la Universidad Complutense de Madrid (http://www.eubd.ucm.es/publicacones/palimp6/index.htm).

\section{Reuniones científicas}

Junto a las publicaciones periódicas y los foros de debate a través de la Red, la amplia gama de reuniones científicas existentes representa uno de los mejores medios para que cualquier profesional o investigador pueda actualizar sus conocimientos u obtener puntual información sobre nuevas experiencias, productos y servicios en su ámbito de actividad.

En este apartado se recogen los datos sobre todos aquellos congresos, jornadas, seminarios, etc., que han publicado sus actas y que se han localizado a través de la consulta de la Bibliografía española. La figura 10 muestra el número de nuevas reuniones científicas por decenios, es decir, en el cómputo no se han tenido en cuenta las diversas ediciones que de un congreso o conferencia hayan tenido lugar.

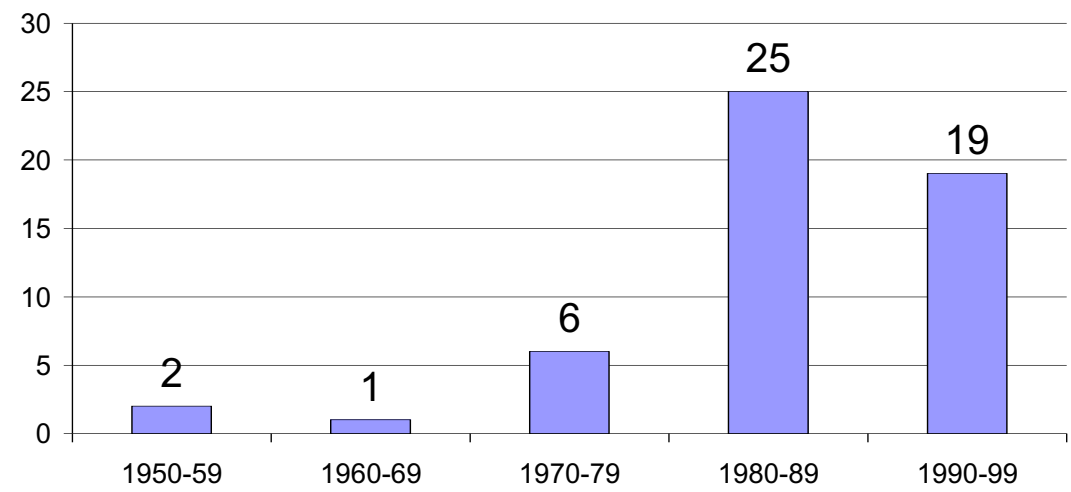

Gráfica 10. Reuniones científicas por decenios 1950-1999

Scire. $7: 2$ (jul.-dic. 2001) 11-38. 
De forma coincidente con los datos que se han recogido en torno a la evolución cuantitativa de las monografías, tesis doctorales y publicaciones periódicas, el punto de inflexión se sitúa en los años ochenta. En la década siguiente se ha consolidado la tendencia apuntada en la precedente.

Al margen de estos datos, en la actualidad existen cerca de diez encuentros estables y consolidados, tres corresponden al ámbito archivístico, dos al estrictamente biblioteconómico, como las Jornadas de Bibliotecas Infantiles y Escolares, que vienen celebrándose desde 1988 y son organizadas por la Fundación Germán Sánchez Ruipérez, y las cinco restantes son iniciativas que pretenden integrar los diferentes sectores vinculados a la Información y Documentación. En este grupo cabría mencionar reuniones plenamente consolidadas como las Jornadas Españolas de Documentación Automatizada, organizadas por FESABID, o las Jornades Catalanes de Documentació. Si bien ambos encuentros no son los únicos que intentan integrar los diferentes sectores relacionados con el mundo de la Información y la Documentación, la revisión de los temas que han presidido sus últimas ediciones sí son un buen referente para mostrar cuáles han sido las principales líneas de investigación por las que se encauza la actividad tanto de los profesionales como de los investigadores del sector.

Una somera revisión de las comunicaciones presentadas a las principales reuniones científicas muestra que existe un conjunto de temas recurrentes como: políticas de información, gestión de centros y formación de profesionales. También desde las primeras ediciones, tanto de las Jornadas Españolas de Documentación Automatizada como de las Jornades Catalanes de Documentació, paralelamente a los temas ya mencionados ha existido un constante interés sobre la contribución de las tecnologías en la gestión de información. Pese a ese interés general se percibe claramente una evolución. Así, desde la atención prestada a la automatización de las unidades de información y a la elaboración y consulta de bases de datos online, se ha pasado a un creciente interés por la información electrónica en general (generación, procesamiento difusión y formación de usuarios en el manejo de recursos de información electrónica). Actualmente el interés se focaliza cada vez más en descubrir las potencialidades de Internet en nuestro ámbito. Junto al protagonismo constante de las tecnologías, también ha destacado la atención prestada a temas como el valor de la información en los entornos empresariales, así como la evaluación de la calidad de los servicios de información en las organizaciones.

\section{A modo de conclusión}

A continuación esbozamos las tendencias que se detectan después de haber realizado esta revisión.

Scire. $7: 2$ (jul.-dic. 2001) 11-38. 
1. Crecimiento: Este ha sido muy importante en los últimos diez años, en todos los núcleos presentados —asociaciones profesionales, núcleos docentes, literatura científica: proyectos, revistas, monografias y tesisy también en las reuniones científicas. Por lo tanto se puede afirmar que la investigación en el ámbito de la Información y la Documentación ha despegado en el último decenio.

2. Consolidación: Todos los núcleos expuestos se han asentado, sobre todo gracias a la puesta en funcionamiento de los estudios universitarios de primero, segundo y tercer ciclos, aunque éstos últimos son todavía pocos e incipientes, y, por lo tanto, las tesis doctorales son escasas. Debido fundamentalmente a lo expuesto anteriormente y a la toma de conciencia o a la nueva percepción de la importancia y la necesidad de la documentación en cualquier actividad productiva, surge una...

3. Especialización: En ella podemos distinguir entre la investigación académica propiamente dicha, dentro del ámbito general de la documentación (gestión, evaluación, lingüística documental, estudios de usuarios, estudios bibliográficos, etc.) y la extensión de la investigación a ámbitos de aplicación concretos (ciencia, medios de comunicación, empresa, salud, tecnología, etc.). Esta aplicación abre un campo muy interesante de exploración y muy provechoso por su aplicación práctica e inmediata.

4. Nuevos protagonistas: Finalmente, la incipiente implicación de otros protagonistas - fundamentalmente, el entorno profesional-empresarial y los responsables políticos-, que han de marcar las políticas nacionales de información y documentación, junto con el entorno académico y docente (universidades, escuelas e institutos de investigación) el profesional (Asociaciones, Colegios profesionales), y el profesional-empresarial.

En este contexto, la universidad debe intentar ser cada vez más competitiva y responder a esta competitividad mediante un incremento de la calidad, tanto a nivel docente como investigador. Tiene que ayudar a las empresas proporcionándoles personal capaz, bien formado, que sepa documentarse e informarse correctamente, que sepa dónde buscar la información y cómo valorarla, que se adapte a las necesidades cambiantes de la llamada sociedad de la información. Pero a su vez, la empresa necesita realizar investigaciones, obtener resultados que puedan aplicarse; y ello lo puede conseguir bien con investigadores propios, o bien contratando, becando o mediante convenios de colaboración con los núcleos docentes, principalmente con las universidades y los institutos de investigación. 
Pero no sólo las universidades y las empresas deben colaborar estrechamente, sino que los gobiernos tienen que elaborar políticas de información y documentación y de investigación. Como señala Fluxá (1996. p. 899-900):

Las empresas y el gobierno están en deuda con la universidad. No puede mantenerse un nivel alto de investigación y por ende de saberes propios, sin una cooperación plena de los tres: universidades, empresas y gobierno. La reingeniería del entorno investigador debe pasar, desde gobierno y empresas, por un incremento en la productividad investigadora de la universidad y esto es cooperación altruista, pero con un legítimo interés en los resultados, que permitirán la auténtica competitividad.

[...] Declarado el valor del recurso saber y su alimento, la información, no sobra expresar la conveniencia de una acción estratégica en éste ámbito. Como en el campo de la competencia ha devenido transnacional, la estrategia debería plantearse a nivel nacional, al menos. Parece justificada la necesidad de una política de información.

\section{Notas}

(1) Aunque la Escuela de Diplomática fue fundada en 1856 y otorgaba el título de paleógrafo que permitía ejercer en bibliotecas y archivos, en 1858 se creó el Cuerpo Facultativo de Archivos y Bibliotecas, ampliado posteriormente a los Arqueólogos (como se redenominó a los anticuarios).

(2) La bibliografía y títulos de este estudios, está recogida en la revista Documentación de las Ciencias de la Información, $\mathrm{n}^{\circ} \mathrm{V}$ de 1981, (Documentación de las Ciencias de la Información, 1981, p. 13-21).

(3) La suma de la Informática, telecomunicaciones y documentación.

(4) En 1989 en un artículo publicado en la revista Education for Information, Mercedes Caridad y Paloma Portela explicaban las asociaciones existentes en aquel momento y remarcaban la importancia que habían tenido y aún tenían las asociaciones profesionales: "The importance of associations to a profession which enjoys little social or economic recognition has been and still is considerable" (Caridad y Portela, 1989, p. 275).

(5) En 1989 se añade el término Documentalistas a la Asociación de Archiveros, Bibliotecarios y Museólogos (ANABA), creada en 1949 y consolidada en 1978.

(6) Actualmente aglutina a trece asociaciones de distintas zonas geográficas de todo el Estado.

(7) Tiene su origen en la Agrupació d'Antics Alumnes i Ex alumnes de l'Escola de Bibliotecaris de Barcelona. En 1999 se fusionó con la Societat Catalana de Documentació i Informació SOCADI.

(8) Esta Escuela impartía dos tipos de cursos, el de Ayudantes de Documentación, de un año de duración y dirigido a Bachilleres, y el curso de Documentalistas, de dos años de duración y dirigido a licenciados, con dos especialidades: archivos y bibliotecas. 
(9) Cambió su orientación, realizando dos cursos, el de Biblioteconomía y Documentación y el de Archivística y Documentación, dirigidos principalmente a Licenciados de disciplinas humanísticas.

(10) Esta escuela no tuvo, en un principio, influencia más allá del territorio catalán, por tres razones fundamentalmente, “(...) sus reducidas dimensiones, el hecho de no conceder título universitario y la exigencia de una licenciatura para acceder al Cuerpo", (Abadal, 1994: 16), a pesar de que hasta 1982 fue la única respuesta docente de todo el Estado, con excepción de la Escuela de Bibliotecarias de la Universidad de Navarra (privada), que funcionó de 1968 a 1979. Un dato significativo en este pequeño recorrido histórico de la Biblioteconomía y la Documentación es que la introducción de la asignatura de Documentación dentro del plan de estudios no se produce hasta el curso 1967-68.

(11) Con la aprobación de un nuevo plan de estudios en 1981, la asignatura de Documentación pasó de troncal a optativa y de quinto curso a segundo.

(12) Véase Caridad et al (1999, p. 234 ss., Fuentes-Jimenez-González (1999, p. 215 ss) y Abadal-Miralpeix (1998, p. 29-30).

(13) La Universidad de Zaragoza oferta un doctorado en este campo, en el marco de la Facultad de Filosofía y Letras, aunque no dispone de la licenciatura en Documentación.

\section{Referencias}

Abadal, Ernest (1994). La Documentación en España. Madrid : CINDOC-FESABID, 1994.

Abadal, Ernest; Miralpeix, Concepció (1989). La enseñanza de la biblioteconomía y la Documentación en la universidad española a finales de los noventa. // Sextas Jornadas Españolas de Documentación. Valencia, 1998. 29-47.

Abellán García, Antonio; Serrano Mascarate, Esmeralda; Ernica Lafuente, Emilio (1997). El estado actual de la investigación en información y documentación en España, Europa, EEUU y algunos países iberoamericanos: proyectos de investigación sobre información, documentación y biblioteconomía entre los años 1990-1996. // Primeras Jornadas Andaluzas de Documentación, JADOC'97. Sevilla : 1997. P. 49-59.

Caridad, Mercedes ; et al. (1999). Breve panorama actual sobre la documentación en España (excepto Cataluña) // BIBLIODOC 1999, Anuari de Biblioteconomia, Documentació i Informació. Barcelona: COBDC, 1999. P. 233-260.

Caridad, Mercedes; Portela, Paloma (1989) The documentalist in Spain. // Education for information. 7 (1989. )273-280.

Cid, Pilar ; Recorder, Maria José (1999). La participació dels professionals de la biblioteconomia i la documentació en les Jornades Catalanes : catorze anys de ponències, comunicacions i experiències. // Setenes Jornades Catalanes de Documentació. Barcelona: COBDC, 1999. 227-239.

Espelt, Constança; Pons, Amadeu. (1997) La formació universitària en biblioteconomia i documentació a Espanya: estat de la qüestió. // Anuari SOCADI de documentació i informació. Barcelona: SOCADI, 1997. 29-39.

Scire. $7: 2$ (jul.-dic. 2001) 11-38. 
Fluxá, José Ma . (1996). Relación entre documentación e investigación en la universidad y en la empresa. // Quintas Jornadas Españolas de documentación automatizada. Cáceres: 1996. 895-901.

Fuentes i Pujol, Ma . Eulàlia ; Jimenez López, Ma. Angels ; González Quesada, Alfons (1999). Breu història i estat actual de la documentació a Catalunya. // BIBLIODOC 1999, Anuari de Biblioteconomia, Documentació i Informació. Barcelona: COBDC, 1999. 215-232.

Fuentes i Pujol, Ma. Eulàlia (1997). Documentación y periodismo. Pamplona: EUNSA, 1997.

Fuentes i Pujol, Ma. Eulàlia (1990). Estudios y formación especializada de los científicos de la información: docencia e investigación. // Terceras Jornadas Españolas de documentación automatizada. Palma de Mallorca : 1990. 187-215.

Gómez Hernández, José A. (1996). Estudio de la investigación española reciente sobre bibliotecas universitarias. // Quintas Jornadas Españolas de Documentación Automatizada. Cáceres, 1996. 985-994.

Pons, Amadeu (1996). Aproximació a una bibliografia espanyola en biblioteconomia i documentació (1990-1995). [Barcelona] : Escola Universitària Jordi Rubió i Balaguer de Biblioteconomia i Documentació, 1996.

Recoder, Maria José; Cid, Pilar (1998). Los intereses profesionales de los bibliotecarios y documentalistas en España a través de su participación en las Jornadas Españolas de Documentación Automatizada: doce años de ponencias, comunicaciones y experiencias. // Sextas Jornadas Españolas de Documentación Automatizada. Valencia: FESABID, 1998. 219-231. 